九州大学学術情報リポジトリ

Kyushu University Institutional Repository

\title{
Measurement and correlation of solubilities for trifluoromethylbenzoic acid isomers in supercritical carbon dioxide
}

Higashi, Hidenori

Department of Chemical Engineering, Faculty of Engineering, Kyushu University

Iwai, Yoshio

Department of Chemical Engineering, Faculty of Engineering, Kyushu University

Miyazaki, Kaoru

Department of Chemical Engineering, Faculty of Engineering, Kyushu University

Ogino, Yoshiyuki

Department of Chemical Engineering, Faculty of Engineering, Kyushu University

他

http://hdl. handle. net/2324/12530

出版情報：Journal of Supercritical Fluids. 33 (1)，pp.15-20，2005-01. Elsevier バージョン：

権利関係: (C) 2004 Elsevier B.V. All rights reserved. 
Revised manuscript for Journal of Supercritical Fluids (RS-04-09)

\section{Measurement and correlation of solubilities for}

\section{trifluoromethylbenzoic acid isomers in supercritical carbon dioxide}

Hidenori Higashi, Yoshio Iwai*, Kaoru Miyazaki, Yoshiyuki Ogino, Miyuki Oki and Yasuhiko Arai

Department of Chemical Engineering, Faculty of Engineering, Kyushu University 6-10-1 Hakozaki Higashi-ku, Fukuoka 812-8581, JAPAN

E-mail : iwai@chem-eng.kyushu-u.ac.jp, Fax : +81-92-642-3496

$\begin{array}{lr}\text { Text } & \text { p.1-11 } \\ \text { Table } & 1-4 \\ \text { Figure } & 1-5\end{array}$




\begin{abstract}
The solubilities of 2-, 3- and 4-trifluoromethylbenzoic acids in supercritical carbon dioxide were measured at 308.2, 313.2 and $323.2 \mathrm{~K}$ by a flow-type apparatus. The pressure range of the measurement was from 9 to $23 \mathrm{MPa}$. The enhancements of solubility by fluorination were markedly observed for 2- and 3-trifluoromethylbenzoic acids. The solubilities of 4trifluoromethylbenzoic acids are almost the same as those of 4-methylbenzoic acid. The experimental data were correlated by the Peng-Robinson equation of state. The correlated results show good agreement with the experimental data by adjusting binary interaction parameters. The results can represent the tendency of solubility enhancement. The interaction parameter between carbon dioxide and 3-trifluoromethylbenzoic acid is smaller than that between carbon dioxide and 2-trifluoromethylbenzoic acid or methylbenzoic acid isomers. While the estimated sublimation pressure for 4-trifluoromethylbenzoic acid is smaller than those for the other compounds, the solubilities of 4-trifluoromethylbenzoic acids are almost the same as those of 4methylbenzoic acid. The interaction parameter between carbon dioxide and 4trifluoromethylbenzoic acid show the negative values. This fact indicates that the interaction between carbon dioxide and 4-trifluoromethylbenzoic acid is stronger than those between carbon dioxide and the other compounds.
\end{abstract}

Keywords : experiment, correlation, solubility, trifluorobenzoic acid, superciticical carbon dioxide 


\section{Introduction}

Supercritical fluid technology has been actively applied and used commercially in extraction, fractionation and purification processes. In particular, supercritical carbon dioxide is frequently used, because it can be used under relatively mild conditions. The supercritical carbon dioxide also has received much attention as a reaction medium. The enhancement of reaction rate is expected by adding of catalysts. However, the solubilities of catalysts usually used in organic solvents are very low in supercritical carbon dioxide. The solubility enhancements by fluorination have been reported by several papers [1-5]. The interactions between carbon dioxide and fluorinated compounds have been investigated and the reason of the solubility enhancement due to specific interactions remains controversial [6, 7]. No reveal specific interaction was observed by a IR spectroscopic study [8] and a NMR study [9], while another NMR study [10] concluded that the specific interaction between carbon dioxide and fluorine existed. Fried and $\mathrm{Hu}$ [11] applied an ab initio calculations and indicated the favourable interaction between carbon dioxide and polar fluoromethyl group of trifluoroethane and trifluoropropane and suggested that quadrupole-dipole interaction is an important contribution to the total energy of interaction. Galand and Wipff [12] performed molecular dynamics simulation and concluded the enhancement of the carbon dioxide-philicity upon fluorination does not stem from enhanced the individual interaction with the carbon dioxide molecule, but from the higher coordination number due to the increase of solvent accessible surface.

The solubility data of fluorinated compounds are very few and the mechanism for the enhancement of solubilitiy has not been yet clarified. In this work, the solubilities of 2-, 3- and 4trifluoromethylbenzoic acids in supercritical carbon dioxide were measured and were compared with those of non-fluorinated compounds. The experimental data were correlated by the PengRobinson equation of state. The interaction parameters were adjusted by the solubility data. 


\section{Experiment}

Materials. Extra pure grade of 2-trifluoromethylbenzoic acid, and guaranteed reagent grade of 3-trifluoromethylbenzoic acid and normal grade of 4-trifluoromethylbenzoic acid, which were supplied by Tokyo Kasei Kogyo Co., Ltd, were used. The purities of 2-, 3- and 4trifluoromethylbenzoic acids were more than $98 \%$. Impurities in trifluoromethylbenzoic acid isomers were extracted by supercritical carbon dioxide. The remained samples were used for the measurements. High-purity carbon dioxide (more than 99.9\%, Sumitomo Seika Co.) was used as received.

Solubility. Two flow-type apparatuses were used to determine the solubilities of solid solutes in supercritical carbon dioxide. Detailed descriptions of the equipments and operating procedures have been given elsewhere $[13,14]$. A main difference of the two apparatus is only the capacities of equilibrium cells. The total volume of the equilibrium cells in apparatus A was about 220 $\mathrm{cm}^{3}$ [13] and that in apparatus $\mathbf{B}$ was about $315 \mathrm{~cm}^{3}$ [14]. The schematic diagram of the apparatus mainly used in this study (apparatus A) was shown in Figure 1. From a cylinder(1), carbon dioxide was supplied and was liquefied through a cooling unit(5). The liquefied carbon dioxide was sent to a preheater(10) by a high-pressure pump(6). When carbon dioxide passed through the preheater, it became a supercritical fluid. Then supercritical carbon dioxide entered into equilibrium cells $(11,12)$. The preheater and equilibrium cells were immersed into a water bath(15) which was controlled within $\pm 0.1 \mathrm{~K}$. The details of equilibrium cells are given in the previous paper [13]. Solid solute was packed into the cell with glass beads to prevent channeling. When supercritical carbon dioxide passed through the equilibrium cells, supercritical carbon dioxide was in contact with the solid solute under equilibrium pressure. The equilibrium pressure was measured by a Bourdon gauge(8) which was calibrated against a strain pressure gauge. 
Supercritical carbon dioxide containing the solute was decompressed through an expansion valve(V8) and then introduced into a U-shaped glass tube in which gaseous carbon dioxide and the solid solute were separated. Usually $0.1-0.4 \mathrm{~g}$ of solute was trapped, and the flow rate of carbon dioxide at outlet of the apparatus was adjusted to be $1-12 \mathrm{~cm}^{3} / \mathrm{s}$. The volume of carbon dioxide was measured by a wet gas meter(14) with the scale to $1 \mathrm{~cm}^{3}$. Then, any small amount of solute precipitated in the expansion valve was removed by using pure carbon dioxide gas and trapped. The amount of solute trapped was determined with an electric balance with the scale to

$10^{-4} \mathrm{~g}$. The solubilities were determined from the weight of the solute and the volume of carbon dioxide. The solubility was slightly higher in the initial stage of the experiments, because of the influence of impurities. The solubilities in the present study were determined after the solubilities attained a constant value.

Melting Temperature and Heat of Fusion. The melting temperature and heat of fusion for these compounds used for the correlation were measured under atmospheric pressure by a differential scanning calorimeter (Shimadzu Co., Ltd., DSC-50). The trifluoromethylbenzoic acid was put in a aluminum pan after crushed. The weights of sample packed in the pans were about $7 \mathrm{mg}$ and the temperature rising rate was set to $1 \mathrm{~K} \mathrm{~min}^{-1}$.

\section{Results and Discussion}

The experimental results for solubilities of 2-, 3- and 4-trifluoromethylbenzoic acids are shown in Table 1 and Figures 2-5. Literature data [3, 15, 16, 17] for solubilities of benzoic acid and methylbenzoic acid isomers are also shown in the figures. It was ascertained that the solubilities obtained were almost independent of the flow rates at the each condition. The solubilities are averaged by several runs at each pressure. The solubilities of 2- and 3trifluoromethylbenzoic acids are about 2 and 10 times higher than those of benzoic acid, 
respectively. The solubilities of 4-trifluoromethylbenzoic acid are about one tenth those of benzoic acid as shown in Figure 2. The enhancement for solubilities of 3-trifluoromethylbenzoic acid is much higher than those of 2-trifluoromethylbenzoic acid. The solubilities of 2trifluoromethylbenzoic acid are about twice those of 2-methylbenzoic acid, and the solubilities of 3-trifluoromethylbenzoic acid are about 10 times those of 3-methylbenzoic acid as shown in Figures 3 and 4, respectively. The solid phase was disappeared above $14 \mathrm{MPa}$ for 3trifluoromethylbenzoic acid at $323.2 \mathrm{~K}$. The solubilities of 4-trifluoromethylbenzoic acids are almost the same as those of 4-methylbenzoic acid as shown in Figure 5.

\section{Correlation}

The following fundamental equation can be used to calculate the solubilities of high-boiling compounds in supercritical fluid.

$$
y_{2}=\frac{P_{2}^{\text {sub }}}{P} \cdot \frac{1}{{\phi_{2}}^{\mathrm{G}}} \exp \left(v_{2}{ }^{\mathrm{s}} \frac{P-P_{2}^{\mathrm{sub}}}{R T}\right)
$$

where $R$ is the gas constant. $P$ and $T$ denote the equilibrium pressure and temperature. $P_{2}^{\text {sub }}$ and $v_{2} \mathrm{~S}$ are the sublimation pressure and solid-state molar volume of solute, respectively. The value of solid-state molar volume was estimated by the group contribution method of Immizi and Perini[18] and the sublimation pressure was calculated by the method proposed by Neau et al.[19]. Namely, the following equation was used to calculate the sublimation pressure.

$$
\ln \left(\frac{P_{2}^{\text {sub }}}{P_{2}^{\mathrm{t}}}\right)=-\frac{\Delta h_{2}^{\mathrm{sub}}}{R}\left(\frac{1}{T}-\frac{1}{T_{2}^{\mathrm{t}}}\right)
$$

where $\Delta h^{\text {sub }}$ is the heat of sublimation calculated by the sum of the heats of fusion and vaporization. $P_{2}{ }^{\mathrm{t}}$ and $T_{2}{ }^{\mathrm{t}}$ denote the triple point pressure and temperature, respectively. The triple point temperature was approximated by the normal melting temperature. The Peng-Robinson 
cubic equation of state[20] was used to calculate the heat of vaporization by adopting the Clausius-Clapeyron equation. The Peng-Robinson equation was given by the following equation.

$$
P=\frac{R T}{v-b}-\frac{a}{v(v+b)+b(v-b)}
$$

where $a$ and $b$ are the energy and size parameters that can be calculated with the critical properties $P_{\mathrm{C}}$ and $T_{\mathrm{C}}$ and acentric factor $\omega$.

The fugacity coefficient of solute in the pressurized gas phase $\phi_{2}{ }^{\mathrm{G}}$ is usually evaluated by adopting an equation of state. The Peng-Robinson equation was also adopted to calculate the fugacity coefficient. In order to apply the Peng-Robinson equation to a binary system, the following mixing and combining rules for the constants $a$ and $b$ were used.

$$
\begin{aligned}
& a=\sum_{i} \sum_{j} X_{i} X_{j} a_{i j}, \quad a_{i j}=\left(1-k_{i j}\right) \sqrt{a_{i} a_{j}} \\
& b=\sum_{i} X_{i} b_{i}
\end{aligned}
$$

where $k_{i j}$ denote the interaction parameter between unlike molecules $i$ and $j$. The values of interaction parameter were adjusted by the experimental solubilities.

The calculated results for the solubilities by the Peng-Robinson equation are also shown in Figures 2-5. The melting temperatures and heats of fusion used in this work are listed in Table 2. The properties of pure components and interaction parameters used to calculate the solubilities were listed in Table 3 and the calculated sublimation pressures were listed in Table 4 . The correlations are in good agreement with the experimental data. The interaction parameter between carbon dioxide and 3-trifluoromethylbenzoic acid is smaller than that between carbon dioxide and 2-trifluoromethylbenzoic acid or methylbenzoic acid isomers. The enhancement for solubilities of 2-trifluoromethylbenzoic acid is lower than that of 3-trifluoromethylbenzoic acid, because the interaction between carbon dioxide and 2-trifluoromethylbenzoic acid is lower than 
that of carbon dioxide and 3-trifluoromethylbenzoic acid. The estimated sublimation pressures of 2- and 3-trifluoromethylbenzoic acids are also higher than those of non-fluorinated compounds. However, the estimated sublimation pressures of 4-trifluoromethylbenzoic acid are lower than those of non-fluorinated compounds. The sublimation pressure affects the solubilities. The solubilities of 4-methylbenzoic acid and 4-trifluoromethylbenzoic acid would be very small due to the lower sublimation pressures. While the sublimation pressure of 4-trifluoromethylbenzoic acid is about one tenth to that of 4-methylbenzoic acid, the solubilities of these compounds are almost the same. The interaction parameter between carbon dioxide and 4trifluoromethylbenzoic acid show the negative values. It is indicated that the interaction between carbon dioxide and 4-trifluoromethylbenzoic acid is stronger than that of carbon dioxide and 4methylbenzoic acid.

\section{Conclusion}

The solubilities of three trifluoromethylbenzoic acid isomers in supercritical carbon dioxide were measured. The enhancements of solubility by fluorination were observed for 2- and 3trifluoromethylbenzoic acids. The correlated results by the Peng-Robinson equation of state show good agreement with the experimental data by adjusting binary interaction parameters. The results can represent the tendency of solubility enhancement by fluorination. The interaction parameter between carbon dioxide and 3-trifluoromethylbenzoic acid is smaller than that between carbon dioxide and 2-trifluoromethylbenzoic acid or methylbenzoic acid isomers. The interaction parameter between carbon dioxide and 4-trifluoromethylbenzoic acid show the negative values. This fact indicates that the interaction between carbon dioxide and 4trifluoromethylbenzoic acid are stronger than those between carbon dioxide and the other compounds. 


\section{Acknowledgment}

The present study was supported in part by a Grant-in-Aid for the 21st century center of excellent (COE) program, "Functional Innovation of Molecular Informatics", from the Ministry of Education, Science, Sports and Culture of Japan and a grant provided by NEDO(via JCII) based on the project "Res. \& Dev. of Enviromentally Friendly Tech. Using SCF” of Ind. Sci. Tech. Frontier Program(METI).

\section{References}

[1] K.E. Laintz, C.M. Wai, C.R. Yonker, R.D. Smith, Solubility of fluorinated metal diethyldithiocarbamates in supercritical carbon dioxide, J. Supercrit. Fluids 4 (1991) 194.

[2] T.A. Hoefling, R.M. Enick, E.J. Beckman, Microemulsions in near-critical and supercritical $\mathrm{CO}_{2}$, J. Phys. Chem. 95 (1991) 7127.

[3] A. Laitinen, O. Jauhiainen, O. Aaltonen, Solubility of fluorinated pharmaceuticals in dense carbon dioxide, Org. Process Res. Dev. 4 (2000) 353.

[4] M.P. Krafft, J.G. Riess, Highly fluorinated amphiphiles and colloidal systems, and their applications in the biomedical field. A contribution, Biochimie 80 (1998) 489.

[5] R. Enick, E. Beckman, A. Yazdi, V. Krukonis, H. Schonemann, J. Howell, Phase behavior of $\mathrm{CO}_{2}$-perfluoropolyether oil mixtures and $\mathrm{CO}_{2}$ - perfluoropolyether chelating agent mixtures, J. Supercrit. Fluids 13 (1998) 121.

[6] P. Raveendran, S.L. Wallen, Exploring $\mathrm{CO}_{2}$-philicity: Effects of stepwise fluorination, J. Phys. Chem. B 107 (2003) 1473.

[7] J.E. Brady, P.W. Carr, A study of solvatochromic linear energy relationships in a homologous series of n-alkanes and n-alkylnitriles, J. Phys. Chem. 89 (1985) 1813. 
[8] G.G. Yee, J.L. Fulton, R.D. Smith, Fourier-transform infrared-spectroscopy of molecularinteractions of heptafluoro-1-butanol or 1-butanol in supercritical carbon dioxide and supercritical ethane, J. Phys. Chem. 96 (1992) 6172.

[9] C.R. Yonker, Solution dynamics of perfluorobenzene, benzene, and perdeuteriobenzene in carbon dioxide as a function of pressure and temperature, J. Phys. Chem. A 104 (2000) 685.

[10] A. Dardin, J.M. DeSimone, E.T. Samulski, Fluorocarbons dissolved in supercritical carbon dioxide. NMR evidence for specific solute-solvent interactions, J. Phys. Chem. B 102 (1998) 1775.

[11] J.R. Fried, N. Hu, The molecular basis of $\mathrm{CO}_{2}$ interaction with polymers containing fluorinated groups: computational chemistry of model compounds and molecular simulation of poly [bis(2,2,2- trifluoroethoxy)phosphazene], Polymer 44 (2003) 4363.

[12] N. Galand, G. Wipff, Solvation of benzene derivatives in $\mathrm{SC}-\mathrm{CO}_{2}$ : a molecular dynamics study of fluorination effects, New J. Chem. 27 (2003) 1319.

[13] Y. Iwai, H. Yamamoto, M. Sohda, Y. Tanaka, T. Shimizu, Y. Arai, A flow-type apparatus for measurement solubilities of coal-derived compounds in supercritical fluid, Mem. Fac. Eng., Kyushu Univ. 49 (1989) 175.

[14] Y. Iwai, T. Fukuda, Y. Koga, Y. Arai, Solubilities of myristic acid, palmitic acid, and cetyl alcohol in supercritical carbon dioxide at 35 C, J. Chem. Eng. Data 36 (1991) 430.

[15] W.J. Schmitt, R.C. Reid, Solubility of monofunctional organic-solids in chemically diverse supercritical fluids, J. Chem. Eng. Data 31 (1986) 204.

[16] J.M. Dobbs, J.M. Wong, R.J. Lahiere, K.P. Johnston, Modification of supercritical fluid phase-behavior using polar cosolvents, Ind. Eng. Chem. Res. 26 (1987) 56. 
[17] K.L. Tsai, F.N. Tsai, Solubilities of methylbenzoic acid isomers in supercritical carbon dioxide, J. Chem. Eng. Data 40 (1995) 264.

[18] A. Immirzi, B. Perini, Prediction of density in organic-crystals, Acta Crystallogr. Sect. A 33 (1977) 216.

[19] E. Neau, S. Garnier, L. Avaullee, A consistent estimation of sublimation pressures using a cubic equation of state and fusion properties, Fluid Phase Equilib. 164 (1999) 173.

[20] D. Peng, D.B. Robinson, New 2-constant equation of state, Ind. Eng. Chem. Fandom.15 (1976) 59.

[21] D.C. Ginnings, G.T. Furukawa, Heat capacity standards for the range 14 K to $1200 \mathrm{~K}$, J. Am. Chem. Soc. 75 (1953) 522.

[22] D.H. Andrews, G. Lynn, J. Johnston, The heat capacities and heat of crystallization of some isomeric aromatic compounds, J. Amer. Chem. Soc. 48 (1926) 1274.

[23] B.E. Poling, J.M. Prausnitz, J.P. O’Connel, “The Properties of Gases and Liquids, Fifth Ed.”, McGRAW-HILL, New York, USA, 2001

[24] J. Marrero-Morejon, E. Pardillo-Fontdevila, Estimation of pure compound properties using group-interaction contributions, AIChE J. 45 (1999) 615.

[25] W.C. Edmister, Applied hydrocarbon thermodynamics: part 4 compressibility factor and equation of state, Petrol.Refiner 37(4) (1958) 173. 
Table 1 Experimental results for solubilities of trifluoromethylbenzoic acids in supercritical carbon dioxide

\begin{tabular}{|c|c|c|c|c|c|}
\hline & $308.2 \mathrm{~K}$ & \multicolumn{2}{|c|}{$313.2 \mathrm{~K}$} & \multicolumn{2}{|c|}{$323.2 \mathrm{~K}$} \\
\hline$P[\mathrm{MPa}]$ & $y_{2}[-]$ & $P[\mathrm{MPa}]$ & $y_{2}[-]$ & $P[\mathrm{MPa}]$ & $y_{2}[-]$ \\
\hline \multicolumn{6}{|l|}{ 2-trifluoromethylbenzoic acid } \\
\hline 9.34 & $0.00137^{\text {a) }}$ & 9.84 & $0.00121^{a)}$ & 9.86 & $0.00026^{a)}$ \\
\hline 11.08 & $0.00193^{a)}$ & 11.15 & $0.00195^{a)}$ & 11.33 & $0.00110^{\text {a) }}$ \\
\hline 12.25 & $0.00235^{a)}$ & 12.31 & $0.00240^{\text {a) }}$ & 12.26 & $0.00186^{\text {a) }}$ \\
\hline 13.75 & $0.00270^{a)}$ & 13.94 & $0.00296^{a)}$ & 13.75 & $0.00305^{a)}$ \\
\hline 16.20 & $0.00318^{a)}$ & 16.17 & $0.00369^{a)}$ & 16.11 & $0.00483^{\text {a) }}$ \\
\hline 19.05 & $0.00382^{\text {a) }}$ & 19.04 & $0.00446^{a)}$ & 18.95 & $0.00671^{\text {a) }}$ \\
\hline 22.60 & $0.00415^{a)}$ & 22.59 & $0.00506^{a)}$ & 22.50 & $0.00855^{a)}$ \\
\hline \multicolumn{6}{|l|}{ 3-trifluoromethylbenzoic acid } \\
\hline 9.41 & $0.00551^{b)}$ & 9.64 & $0.00768^{b)}$ & 9.61 & $0.00071^{\text {a) }}$ \\
\hline 9.49 & $0.00985^{\text {a) }}$ & 11.10 & $0.01229^{b)}$ & 11.29 & $0.00719^{a)}$ \\
\hline 11.11 & $0.01384^{b)}$ & 12.20 & $0.01760^{b)}$ & 12.34 & $0.01968^{a)}$ \\
\hline 11.18 & $0.01423^{\text {a) }}$ & 13.85 & $0.02295^{a)}$ & 13.82 & $0.04690^{\text {a) }}$ \\
\hline 12.28 & $0.01643^{b)}$ & 16.38 & $0.03038^{a)}$ & & \\
\hline 13.69 & $0.01907^{b)}$ & 19.09 & $0.03292^{a)}$ & & \\
\hline 16.07 & $0.02354^{b)}$ & 22.54 & $0.03878^{a)}$ & & \\
\hline 16.13 & $0.02298^{a)}$ & & & & \\
\hline 18.94 & $0.02702^{b)}$ & & & & \\
\hline 22.52 & $0.02879^{b)}$ & & & & \\
\hline \multicolumn{6}{|l|}{ 4-trifluoromethylbenzoic acid } \\
\hline 9.68 & $0.000106^{a)}$ & 9.90 & $0.000077^{\text {a) }}$ & 9.80 & $0.000031^{a)}$ \\
\hline 11.23 & $0.000141^{\text {a) }}$ & 11.46 & $0.000137^{\text {a) }}$ & 11.34 & $0.000088^{a)}$ \\
\hline 12.24 & $0.000158^{\text {a) }}$ & 12.37 & $0.000157^{\text {a) }}$ & 12.32 & $0.000144^{a)}$ \\
\hline 13.55 & $0.000187^{\text {a) }}$ & 13.65 & $0.000187^{\text {a) }}$ & 13.73 & $0.000220^{a)}$ \\
\hline 16.09 & $0.000215^{\text {a) }}$ & 16.20 & $0.000231^{\text {a) }}$ & 16.28 & $0.000295^{a)}$ \\
\hline 19.03 & $0.000246^{\text {a) }}$ & 18.93 & $0.000270^{\text {a) }}$ & 18.96 & $0.000381^{a)}$ \\
\hline 22.44 & $0.000286^{a)}$ & 22.29 & $0.000306^{\mathrm{a})}$ & 22.31 & $0.000456^{a)}$ \\
\hline
\end{tabular}

a) measured by apparatus $\mathbf{A}$ [13]

b) measured by apparatus B [14] 
Table 2 Melting temperatures and heats of fusion

\begin{tabular}{|c|c|c|}
\hline Substance & $T_{\mathrm{m}}[\mathrm{K}]$ & $\Delta h^{\text {fus }}[\mathrm{kJ} / \mathrm{mol}]$ \\
\hline benzoic acid & $395.5^{\text {a) }}$ & $18.01^{\text {a) }}$ \\
\hline 2-methylbenzoic acid & $376.9^{b)}$ & $20.17^{b)}$ \\
\hline 3-methylbenzoic acid & $381.9^{b)}$ & $15.73^{b)}$ \\
\hline 4-methylbenzoic acid & $452.8^{b)}$ & $22.72^{b)}$ \\
\hline 2-trifluoromethylbenzoic acid & $380.7^{\text {c) }}$ & $24.0^{c)}$ \\
\hline 3-trifluoromethylbenzoic acid & $376.8^{c)}$ & $18.0^{c)}$ \\
\hline 4-trifluoromethylbenzoic acid & $497.3^{\mathrm{c})}$ & $67.3^{\text {c) }}$ \\
\hline \multicolumn{3}{|l|}{$\overline{a) ~ G i n n i n g s ~ a n d ~ F u r u k a w a[21] ~}$} \\
\hline b) Andrews et al.[22] & & \\
\hline
\end{tabular}


Table 3 Properties of pure components and interaction parameters

\begin{tabular}{|c|c|c|c|c|c|}
\hline Substance & $T_{\mathrm{C}}[\mathrm{K}]$ & $P_{\mathrm{C}}[\mathrm{MPa}]$ & $\omega[-]$ & $v^{\mathrm{S}}\left[\mathrm{cm}^{3} / \mathrm{mol}\right]$ & $k_{i j}$ \\
\hline carbon dioxide & $304.1^{\text {a) }}$ & $7.37^{\text {a) }}$ & $0.225^{\text {a) }}$ & - & \\
\hline benzoic acid & $751.0^{\text {b) }}$ & $4.58^{\mathrm{b})}$ & $0.619^{c)}$ & $92.5^{\mathrm{d})}$ & 0.080 \\
\hline 2-methylbenzoic acid & $749.5^{b)}$ & $3.99^{b)}$ & $0.669^{\mathrm{c})}$ & $107.4^{\text {d) }}$ & 0.096 \\
\hline 3-methylbenzoic acid & $754.1^{b)}$ & $3.90^{\mathrm{b})}$ & $0.672^{c)}$ & $107.4^{\mathrm{d})}$ & 0.104 \\
\hline 4-methylbenzoic acid & $770.3^{b)}$ & $3.90^{\text {b) }}$ & $0.672^{\text {c) }}$ & $107.4^{\text {d) }}$ & 0.130 \\
\hline 2-trifluoromethylbenzoic acid & $717.5^{b)}$ & $2.98^{\mathrm{b})}$ & $0.658^{c)}$ & $118.1^{\text {d) }}$ & 0.092 \\
\hline 3-trifluoromethylbenzoic acid & $704.6^{b)}$ & $2.93^{b)}$ & $0.661^{c)}$ & $118.1^{\text {d) }}$ & 0.057 \\
\hline 4-trifluoromethylbenzoic acid & $681.8^{\mathrm{b})}$ & $2.93^{\mathrm{b})}$ & $0.661^{c)}$ & $118.1^{\text {d) }}$ & - 0.062 \\
\hline
\end{tabular}
a) Poling et al.[23]
b) Group contribution method of Marrero-Pardillo[24]
c) Estimation method of Edmister [25]
d) Group contribution method of Immizi and Perini[18] 
Table 4 Sublimation pressures ${ }^{\text {a) }}$

\begin{tabular}{lccc}
\hline & \multicolumn{3}{c}{$P^{\text {sub }}[\mathrm{Pa}]$} \\
\cline { 2 - 4 } Substance & $308.2 \mathrm{~K}$ & $313.2 \mathrm{~K}$ & $323.2 \mathrm{~K}$ \\
\hline benzoic acid & 0.881 & 1.48 & 3.96 \\
2-methylbenzoic acid & 0.489 & 0.851 & 2.45 \\
3-methylbenzoic acid & 0.514 & 0.871 & 2.39 \\
4-methylbenzoic acid & 0.098 & 0.170 & 0.484 \\
2-trifluoromethylbenzoic acid & 1.00 & 1.73 & 4.90 \\
3-trifluoromethylbenzoic acid & 2.52 & 4.17 & 10.9 \\
4-trifluoromethylbenzoic acid & 0.00650 & 0.0131 & 0.0497 \\
\hline
\end{tabular}

a) Estimated by the method of Neau et al.[19] 


\section{Figure Captions}

Figure 1 Schematic diagram of experimental apparatus.
1. Gas Cylinder
2. Dryer
3. Filter
4. Pressure Gauge
5. Cooling Unit
6. Feed Pump
7. Stopper
8. Precision Pressure Gauge
9. Safety Valve
10. Pre-Heater
11. Pre-Equilibrium Cell
12. Equilibrium Cell
13. Trap
14. Gas Meter
15. Water Bath
V1, 3-7. Stop Valve
V2. Back Pressure Regulator
V8. Expansion Valve

Figure 2 Solubilities of benzoic acid, 2-, 3- and 4-trifluoromethylbenzoic acids in supercritical carbon dioxide at $308.2 \mathrm{~K}$.

Experimental: benzoic acid ( ) Laitinen et al.[3], ( @) Schmitt and Reid[15],

(O) Dobbs et al.[16]; 2-trifluoromethylbenzoic acid ( $\nabla$ ) This work;

3-trifluoromethylbenzoic acid ( $>$ Laitinen et al.[3], ( $\diamond)$ This work;

4-trifluoromethylbenzoic acid ( $\Delta$ ) This work.

Calculated results by the Peng-Robinson equation of state: benzoic acid ( $\longrightarrow$;

2-trifluoromethylbenzoic acid ( - - ) ; 3-trifluoromethylbenzoic acid (.....) ;

4-trifluoromethylbenzoic acid (- - -).

Figure 3 Solubilities of 2-methylbenzoic acid and 2-trifluoromethylbenzoic acid in supercritical carbon dioxide.

Experimental: 2-methylbenzoic acid ( $313.2 \mathrm{~K}$, ( $323.2 \mathrm{~K}$, Tsai and Tsai[17] ; 2-trifluoromethylbenzoic acid ( $\Delta$ 308.2 K, ( $\mathbf{O} 313.2 \mathrm{~K},(\square 323.2 \mathrm{~K}$, This work. 
Calculated results by the Peng-Robinson equation of state:

2-methylbenzoic acid ( — $) 313.2 \mathrm{~K},($..... ) $323.2 \mathrm{~K}$;

2-trifluoromethylbenzoic acid ( - - - $308.2 \mathrm{~K},($ - $\rightarrow 313.2 \mathrm{~K}$, (- . - $323.2 \mathrm{~K}$.

Figure 4 Solubilities of 3-methylbenzoic acid and 3-trifluoromethylbenzoic acid in supercritical carbon dioxide.

Experimental: 3-methylbenzoic acid ( $313.2 \mathrm{~K}$ ( ( $323.2 \mathrm{~K}$, Tsai and Tsai[17] ; 3-trifluoromethylbenzoic acid ( $\Delta$ ) 308.2 K, ( $\mathbf{O} 313.2 \mathrm{~K},(\square 323.2 \mathrm{~K}$, This work.

Calculated results by the Peng-Robinson equation of state:

3-methylbenzoic acid ( — $) 313.2 \mathrm{~K},($ ( ..... ) $323.2 \mathrm{~K}$;

3-trifluoromethylbenzoic acid ( - . - - 308.2 K, ( - - $313.2 \mathrm{~K}$, $(-\cdot-) 323.2 \mathrm{~K}$.

Figure 5 Solubilities of 4-methylbenzoic acid and 4-trifluoromethylbenzoic acid in supercritical carbon dioxide.

Experimental: 4-methylbenzoic acid ( $313.2 \mathrm{~K}$ ( 3 ( $323.2 \mathrm{~K}$, Tsai and Tsai[17] ; 4-trifluoromethylbenzoic acid ( $\Delta$ ) 308.2 K, ( $\mathbf{O} 313.2 \mathrm{~K},(\square 323.2 \mathrm{~K}$, This work.

Calculated results by the Peng-Robinson equation of state:

4-methylbenzoic acid ( — $) 313.2 \mathrm{~K},($ ( ..... ) $323.2 \mathrm{~K}$;

4-trifluoromethylbenzoic acid ( — - - - $308.2 \mathrm{~K},($ - $\rightarrow 313.2 \mathrm{~K}$, (- - - $323.2 \mathrm{~K}$. 


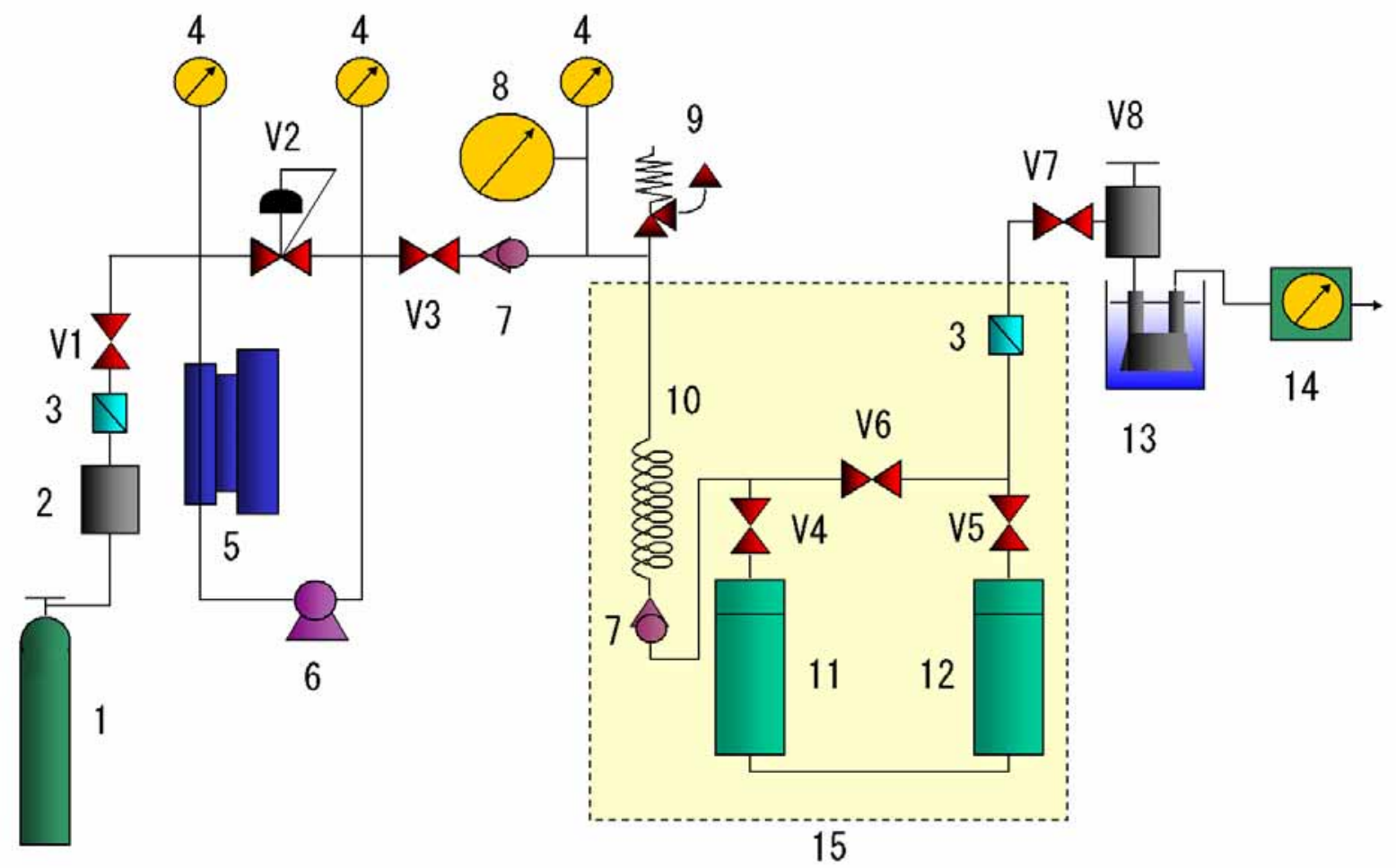

Fig.1 Higashi et al 


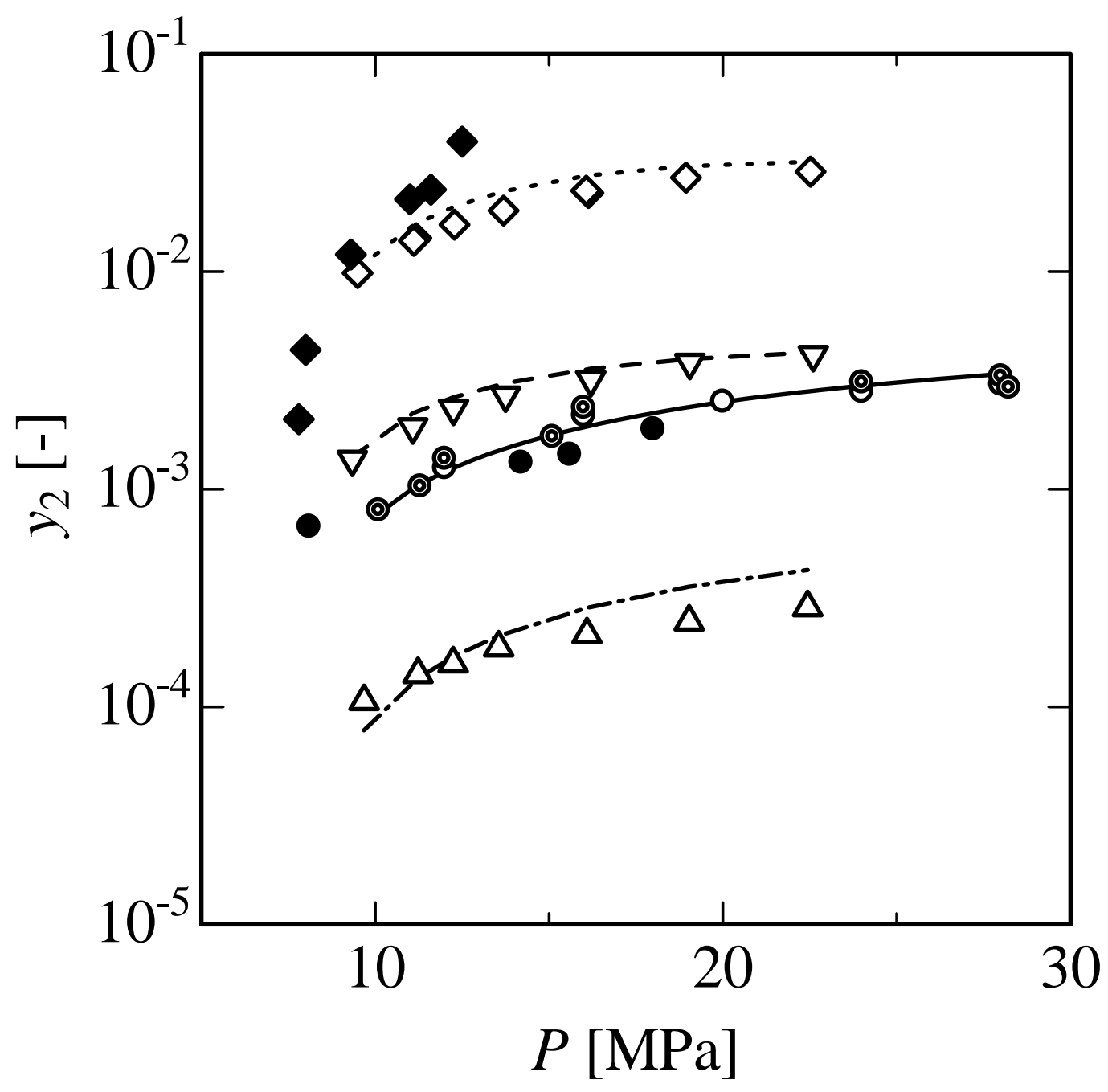

Fig.2 Higashi et al. 


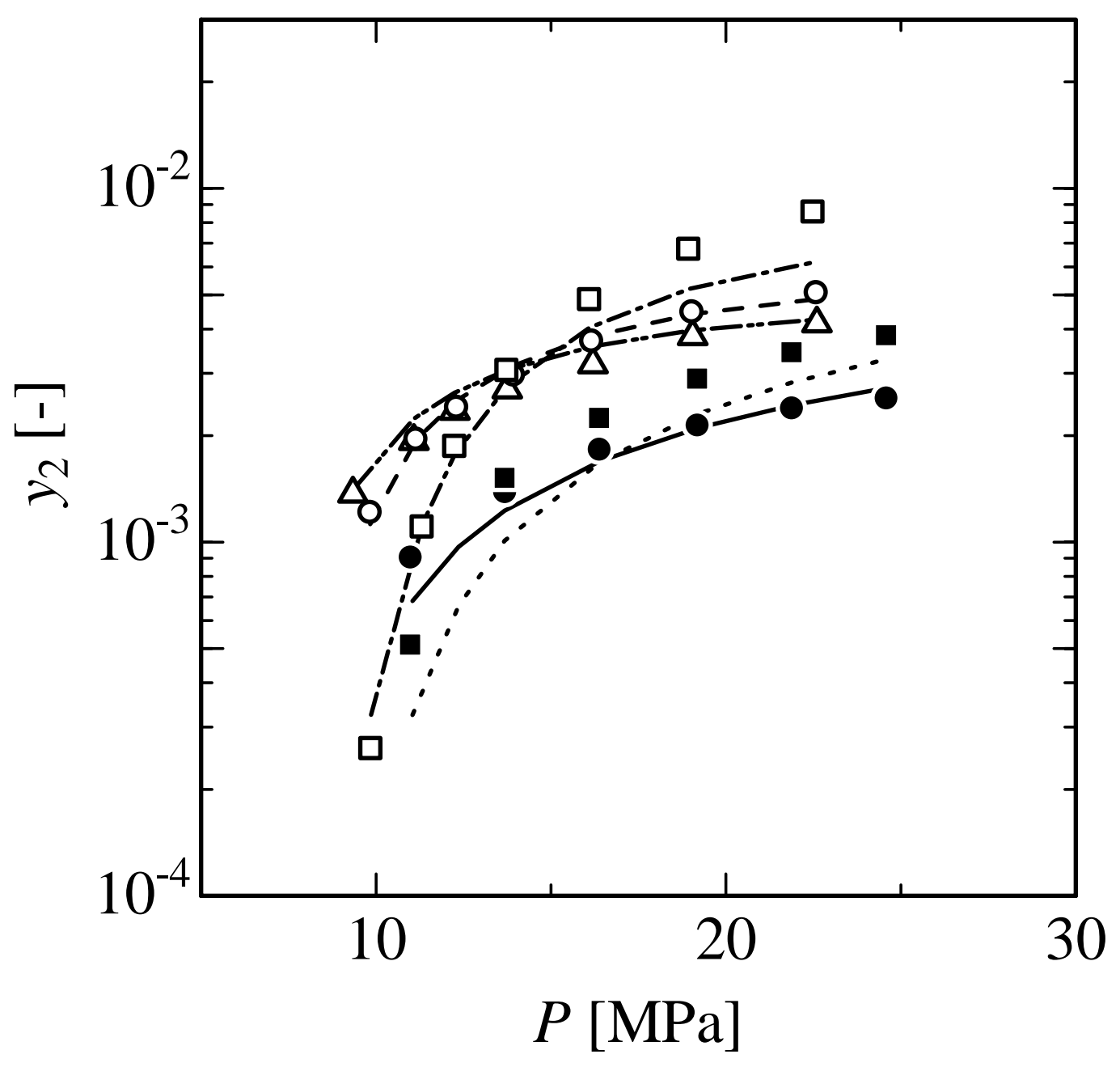

Fig.3 Higashi et al. 


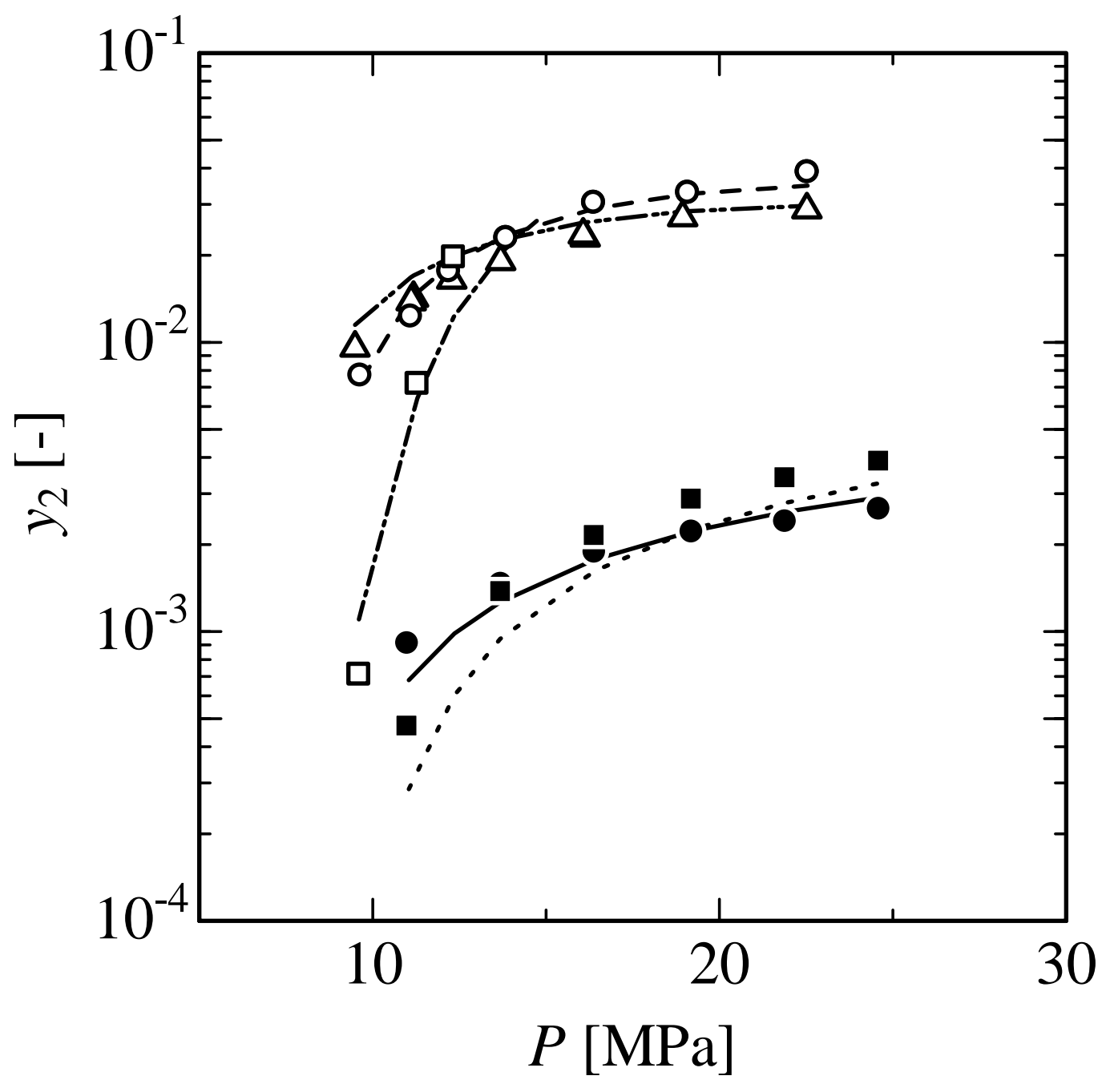

Fig.4 Higashi et al. 


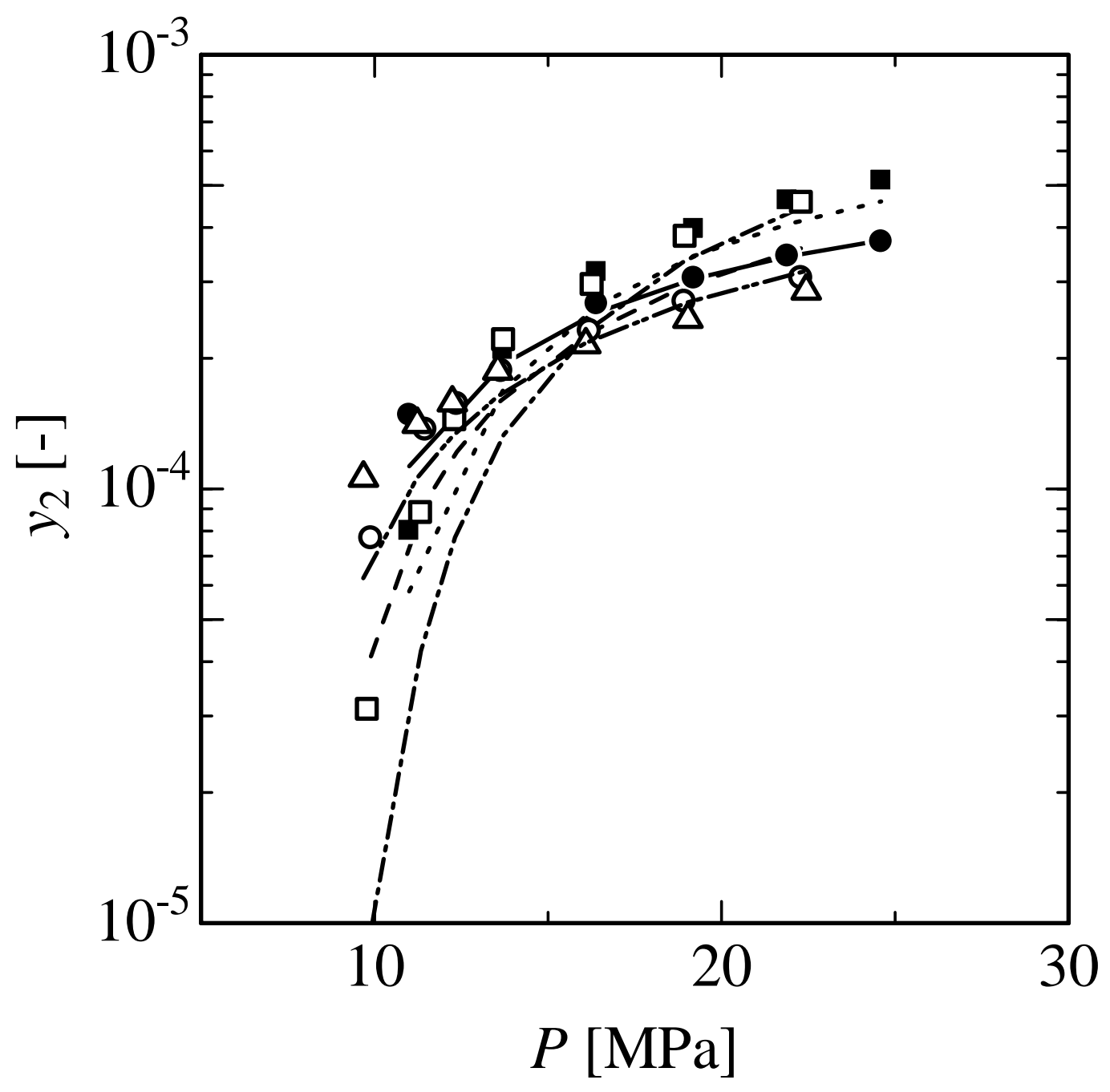

Fig.5 Higashi et al. 